\title{
Cecal Hemorrhage
}

National Cancer Institute

\section{Source}

National Cancer Institute. Cecal Hemorrhage. NCI Thesaurus. Code C78234.

Bleeding originating in the cecum. 